\title{
Analysis Of R.C. Slabs At High Temperature Using Nonlinear Finite Element Method
}

\author{
A. Y. Al-Saati \\ Z. Kh. Awad \\ Kh. I. Mohmmad
}

University of Mosul/College of Engineering/Civil Engineering Department

\begin{abstract}
This paper is concerned with the Non-linear behavior of reinforced concrete slabs at high temperature at service loads. Layered degenerated shell element is used to predict the complex feature of structural behavior at high - temperature condition, such as thermal expansion, cracking, crushing, yielding and changing of materials properties with temperature. In the development of F.E model, the geometrical nonlinearity is considered, the layered element are modified to allow for temperature distribution and change of materials property through thickness .Predictions from this analysis are compared to the available experimental results and good agreements obtained.
\end{abstract}

Keywords: Nonlinear Finite Element, R.C. Slabs, High Temperature

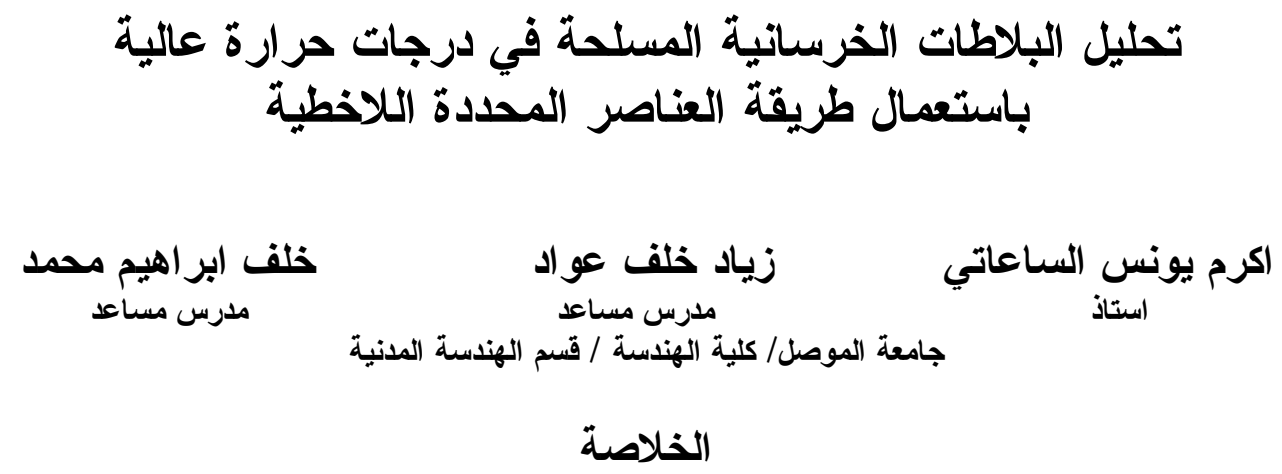

يتضمن هذا البحث در اسة البلاطات الخرسانية تحت نأثير درجات الحرارة العالية و عندما يكون المنثأ تحـــت تأثير أحمال الخدمة. استخدم العنصر القشري متعدد الطبقات لغرض تمثنيل المنشأ و إيجاد السلوك المعقد لله عند التعرض اله

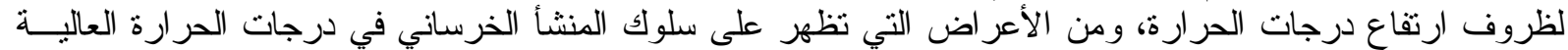

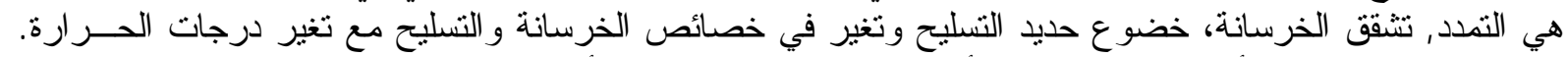

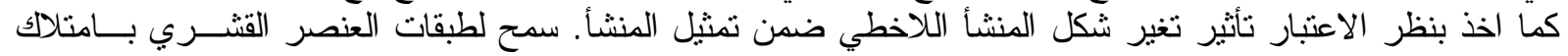

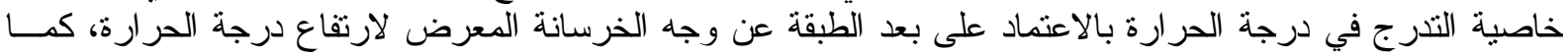

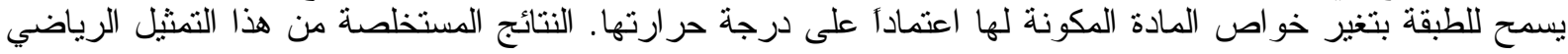

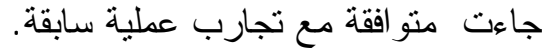




\section{Introduction}

In the last few years, many researche works introduced on the structure behavior and resistance of temperature rising in accidental situations such as nuclear or fire under service loads.The analysis of reinforced concrete structures constitutes an important part in their design. In the analysis, considering high temperature produced from fire, various formulas are usually employed for the fire resistance of structures offered by building codes, without really estimating the thermo - mechanical behavior of structure during fire.

Nizamuddin 1976 [1] developed a non-linear layered F.E. approach based on the Kirchoff (thin plate) theory to model R.C. slabs in the fire environment, for the limiting case of the thin plate, in which plate thickness / span ratio tend to zero.

In 2003, Huang and others [2] used a non-linear layered F.E. procedure for predicting the structural response of R.C. slabs subjected to fire. This procedure is based on mindlineReissner (thick plate) theory, by using biaxial failure envelope for concrete and assuming linear temperature distribution though thickness of slab, this model used in Vulcan program.

Reynourd and Nechnech (2002) [3] introduced an Elasto-plastic damage model of R.C. structure at high temperature. This model depends on thermal coupling procedure with mechanical load including the creep effect with thermal effect on structure. The results predicted were well compared to the experimental results. The procedure is divided in two parts to produce the total effect:

EC2 reduction in reinforcong steel strength.

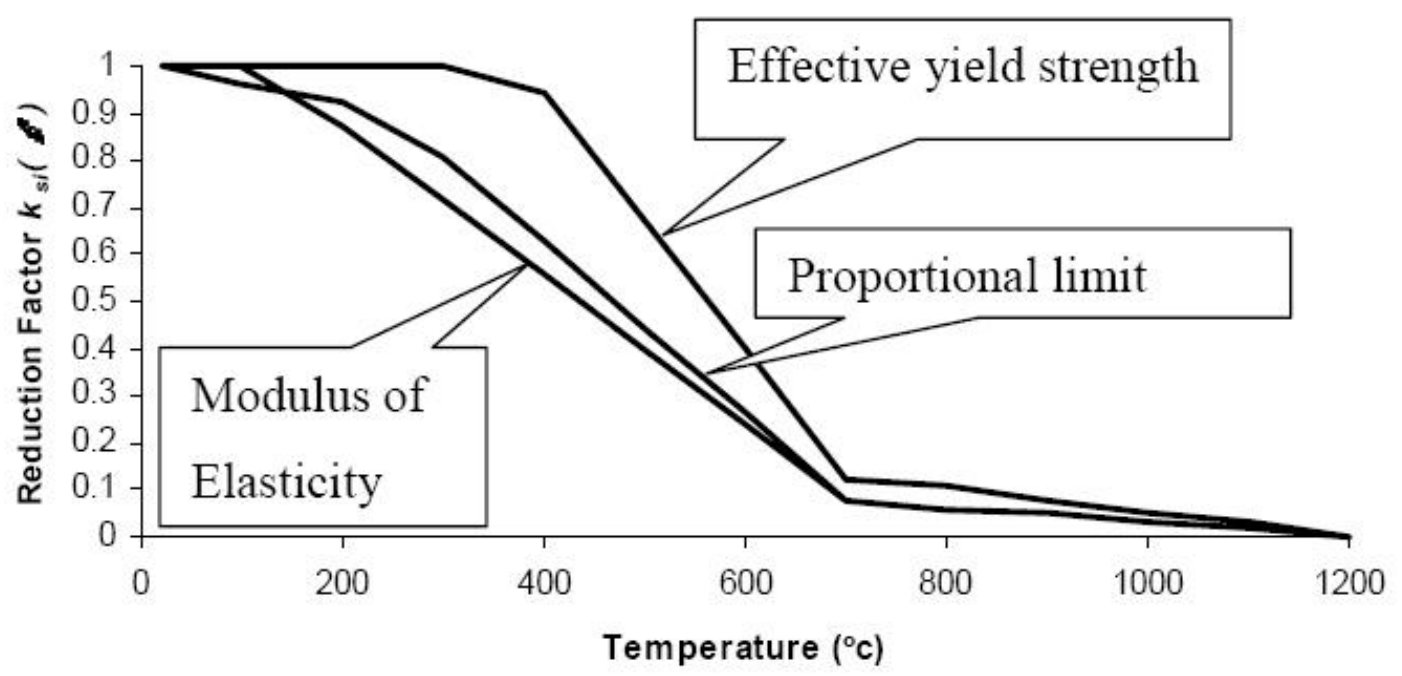

Figure (1) Euro Code-2 reduction factor for steel reinforcement [4]

1. Mechanical damage effect.

2. Non-mechanical damage effect.

Euro Code 2-2002 [4] gives models for the behavior of materials (concrete and steel reinforcement) of different temperature and recommended a reduction factor for steel strength with temperature as shown in fig (1).

Planine and others 2005 [5] develop numerical model for behavior of concrete column in fire condition and comparison with Euro Code 2.

Long and Purkiss 2005 [6] studied some experimental data and model (Adnerbug and themerandersson model, Schineider model, Diederiches model and Khouryand Terro model), 
they made comparison between the above models and proposed a stress - strain - temperature model which incorporate the effect of transient strain implicitly at elevated temperatures. Zha 2002 [7] used F.E. method to calculate fire resistance of columns concrete filled CHS structures with standard BS5990 and DD ENV 1994-1-2 confer the methods to calculate the fire resistance of these members. The temperature distribution in column cross section during fire is calculated by the two dimensional nonlinear F.E. program FIRES-T.

The objective of this paper is to develop a non-linear layered shell element model to simulate the behavior of R.C. structure subjected to temperature rising until failure by crushing, cracking or yielding. The complex features of reinforced concrete structures behavior in fire condition are considered. Also included in the in the work the dimensional changing caused by temperature rising and changing in mechanical properties of the materials with changing temperature. All effects on the geometry and stiffness of the structure, as well as the internal forces, continually change, as the temperature increases are included in the model.

\section{Non - Linear Layered Model}

The structure is modeled, as an assembly of layered shell element. The main assumptions are as follows [8]:

1. The element is consisting of a number of concrete layers and reinforcement layers as shown in fig. (2), no slip exists between layers.

2. Each layer has different temperature through thickness, the associated materials properties and stress - strain relations are function of layers temperature.

3. Reinforcement is modeled by equivalent smeared layer with stiffness only in the direction of reinforcement. The layer temperature is consistent with it position in the concrete thickness (function of concrete cover). All properties and stress-strain relation are dependent on temperature, where reinforcement layer has stiffness in the direction of layer only.

4. Each element node has five degree of freedom corresponding three displacements and two rotations.

The basic analytical aim is to determine the deformation of the nodes $\{U\}$ under external load $\{\mathrm{R}\}$, the basic equilibrium equation at any step (n) that must be satisfied is [8]:

$\{R\}_{n}-\{Q\}_{n}=0$

Where: $\{\mathrm{Q}\}$ is the vector of internal nodal forces.

$\{R\}$ is the vector of external nodal forces.

(n) Number of time step.

In the case of reinforced concrete slabs equation (1) is highly nonlinear, therefore, the non linear equations are solved by an incremental iterative procedure. Calculation of structure stiffness matrix $[K]$ and internal force vector $\{Q\}$ using the standard finite element formulation:

$$
\begin{aligned}
& \overline{\mathrm{K}}=\iint_{-1}^{+1} B^{T} \cdot D \cdot B \cdot J \cdot d \zeta \cdot d A \\
& \mathrm{Q}=\int_{-1}^{+1} \int^{T} \cdot \sigma \cdot J \cdot d \xi \cdot d A=
\end{aligned}
$$


Where:

$$
\int d A=\int_{-1-1}^{+1+1} \int_{-1} d \xi . d \eta
$$

Where: (B) Geometry matrix.

(D) Material matrix.

(J) Jacobian matrix.

$(\zeta, \xi, \eta)$ Natural coordinates.

(A) Area of element.

The total Lagrangian Geometrical nonlinearity is adopted here to enhance the prediction in case of large deflection and buckling that may occur in the structure. The strain - displacement matrix $\mathrm{B}$ is separated into usual infinitesimal parts $B_{0}$ and non-linear contribution $B_{L}$ so that:

$B=B_{0}+B_{L}$

Where $\{Q\}_{\mathrm{n}}$ in equation (1):

$$
\{Q\}_{n}=\int_{v} B^{T} \cdot \sigma_{n} \cdot d v
$$

Taking variation of equation (1) with respect to displacement $(d u)$ gives tangential stiffness matrix for a geometrically non-linear problem:

$K \cdot d u=\int_{v} B^{T} \cdot d \sigma \cdot d v+\int_{v} d B^{T} \cdot \sigma \cdot d v$

Consequently $d B^{T}=d B_{L}{ }^{T}$, therefore the geometry stiffness matrix :

$$
\begin{aligned}
& K_{\sigma} \cdot d u=\int_{v} d B_{L}^{T} \cdot \sigma \cdot d v \\
& K=\bar{K}+K_{\sigma} \\
& \varepsilon=\varepsilon_{0}+\varepsilon_{L}
\end{aligned}
$$




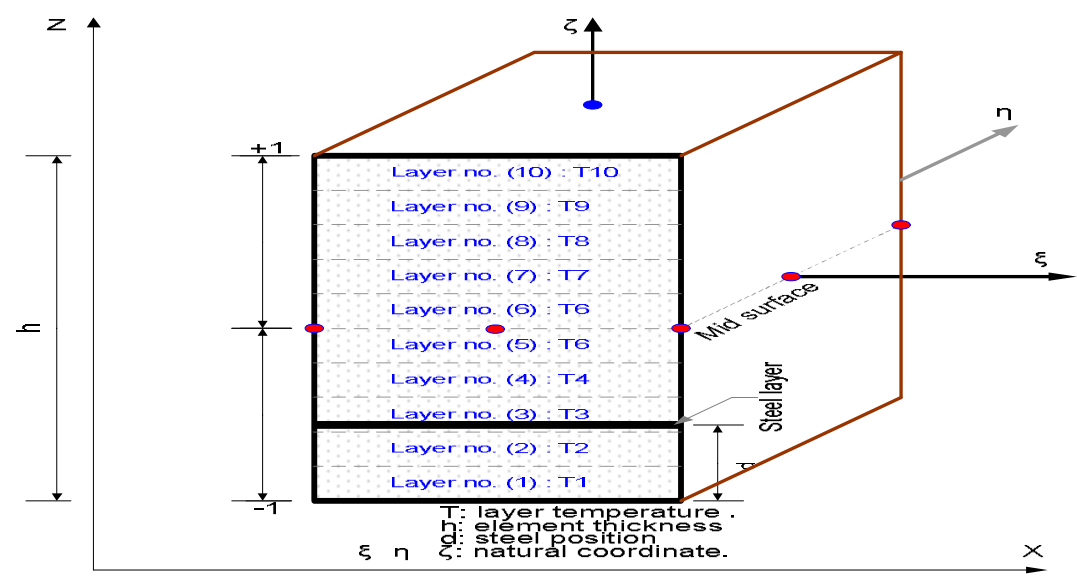

Figure (2) Layered shell element

\section{Numerical Solution Procedure}

In the present study, the total strain at any time $(\mathrm{t})$ is assumed as:

$\varepsilon^{T}=\varepsilon^{m}+\varepsilon^{n m}$

where:

$\varepsilon^{m}:$ Mechanical strain due to external load.

$\varepsilon^{n m}:$ Non mechanical strain due to temperature effect at time $(\mathrm{t})$.

$\varepsilon^{T} \quad$ Total strain at time $(\mathrm{t})$.

Then, the initial strain load vector $\left(\Delta Q_{n}{ }^{n m}\right)$ at time step $\left(t_{n}\right)$ that produce the non - mechanical strain $\left(\Delta \varepsilon_{n}{ }^{n m}\right)$, will be used to find the equivalent nodal forces [9]:

$\Delta Q^{n m}=\int_{v} B^{T} \cdot D \cdot \Delta \varepsilon_{n}{ }^{n m} \cdot d v$

And these nodal forces should be added to the residual forces:

$\Delta R_{n}=\Delta Q_{n}{ }^{n m}+\Delta R_{n-1}{ }^{u}$

where:

$\Delta Q_{n}{ }^{n m}$ : equivalent nodal force.

$\Delta R_{n}$ : total residual forces.

$\Delta R_{n-l}{ }^{u}$ : unbalance forces of (n-1) increment.

At time step $\left(\mathrm{t}_{\mathrm{n}}\right)$ all joint displacement are $\{\mathrm{U}\}$, total strain $\left(\varepsilon_{n}\right)$ and total non mechanical strain:

$\varepsilon_{n}{ }^{n m}=\varepsilon_{n-1}{ }^{n m}+\Delta \varepsilon_{n}{ }^{n m}$

The total mechanical strain in structure at time step $\left(t_{n}\right)$ :

$\varepsilon^{m}{ }_{n}=\varepsilon^{T}-\varepsilon_{n}{ }^{n m}$

\section{Thermal strain:}

At any increasing or decreasing of ambient temperature, materials dimensions change as a function of temperature. For R.C. structure, the concrete has thermal strain coefficient expressed by linear function of temperature [7]: 
$\alpha_{c}=(0.008 * T+6) * 10^{-6}$

Where: $\mathrm{T}$ - temperature $\mathrm{C}^{0}$.

Constant thermal strain coefficient is assumed for steel [10]:

$\alpha_{s}=1.4 * 10^{-5}$

This strain will affect the geometry of loaded structure, therefore the concrete layers will have strain in two directions $(\mathrm{x}, \mathrm{y})$, where temperature assumed to produce zero shear strain. For steel, the strain will be in one direction through the smeared layer (direction of reinforcement).

$\varepsilon_{c}{ }^{\text {th }}=\alpha_{c} *\left(T-T_{0}\right)$

$\varepsilon_{s}^{\text {th }}=\alpha_{s} *\left(T-T_{0}\right)$

In all fire analysis the initial temperature $\left(T_{0}\right)$ is assumed $=20 \mathrm{C}^{0}$.

\section{Materials Constitutive Relationships}

\section{Concrete behavior}

In fig (3), the multi stage of stress strain relationships of concrete in compression at elevated temperature is shown. In this relationship the peak stress decrease with temperature increase.

For concrete at normal temperature the biaxial stress strain envelop of Kupfer and Gerstle expression is adopted. Barzegar - Jamshidi[2] proposed envelop for concrete in biaxial stress in fig. (4), where the compressive strength $\left(f_{c}\right)$ and tensile strength $\left(f_{t}\right)$ are functions of temperature. The failure surface of biaxial strength envelope are divided in to four regions that depend on the stress state as represented by the principle stresses ratio. Compressive stresses are negative and tensile stresses are positive. The behavior of concrete tensile stresses is shown in fig.(5)[2], and it is similar to the uniaxial compression behavior.

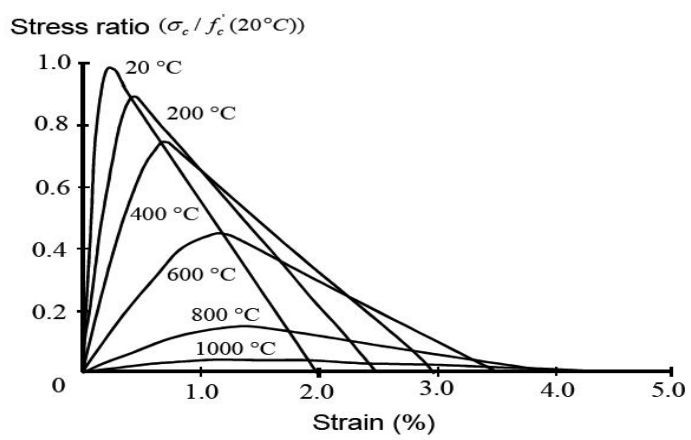

Figure (3) Uiaxial Compression Stress - Strain of concrete[8]

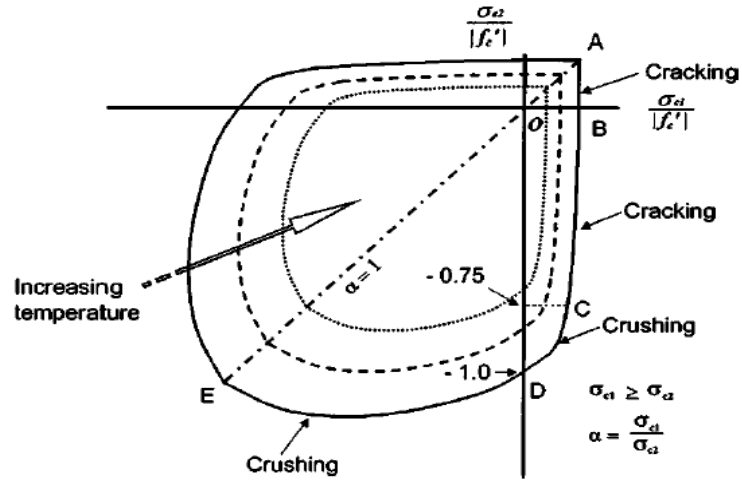

Fig (4) Biaxial envelop of concrete[2]

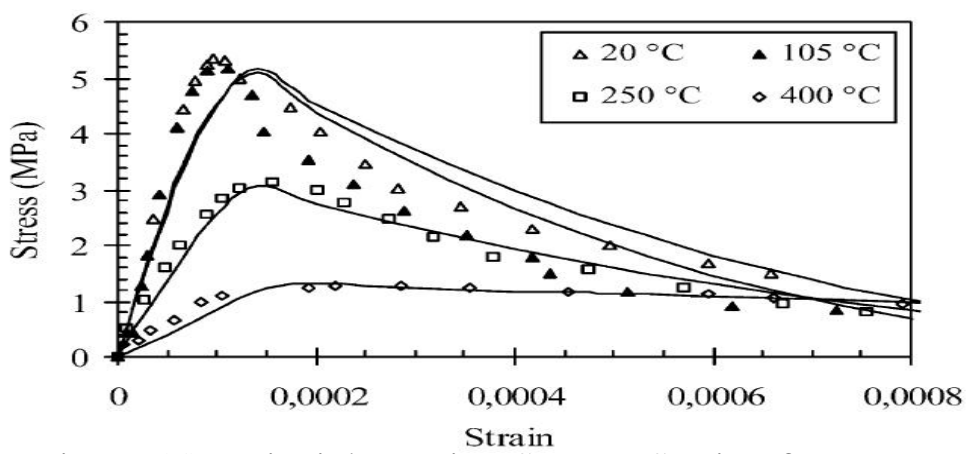

Figure (5) Uniaxial Tension Stress - Strain of concrete[7] 


\section{Al-Saati: Analysis Of R.C. Slabs At High Temperature Using Nonlinear Finite Element}

\section{Concrete modeling}

The tensile strength of concrete is assumed to be change with temperature as shown in fig. (6). Where no change in tensile strength when the temperature is less than $100 \mathrm{C}^{0}$. In fig. (8) The compressive strength change with temperature is shown. Constant compression strength is maintained below $120 \mathrm{C}^{0}$. The reduction in strength due to temperature rising is assumed and it is noticed that there is a reduction in the elastic modulus of concrete is as shown in fig. (7).

\section{Uniaxial Steel model}

In this study, the steel is modeled as equivalent layer with stiffness only in the direction of reinforcement. Perfect bond between steel and concrete layers is assumed. The stress - strain relationship for steel is shown in fig. (9) [2]. In fig (10) shown that the steel yield strength is assumed constant when its temperature is less than $350 \mathrm{C}^{0}$ and Steel elastic modulus 1 is constant when steel temperature less than $200 \mathrm{C}^{0}$; Steel material loss its strength when the temperature exceed $800 \mathrm{C}^{0}$ as shown in fig. (11) [2].

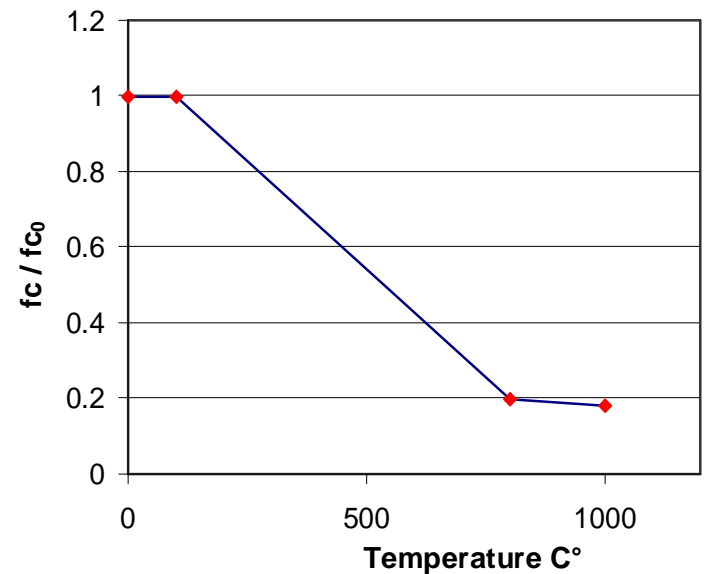

Figure (6) Concrete Tensile strength

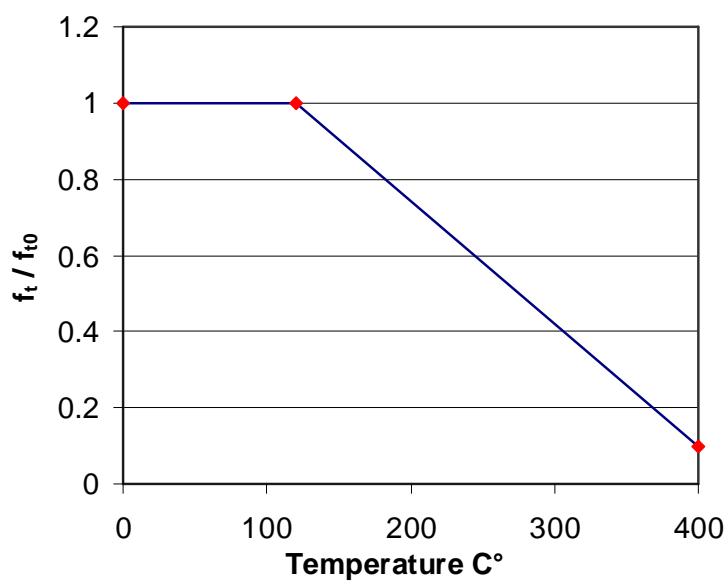

Figure (8) Concrete Compressive strength

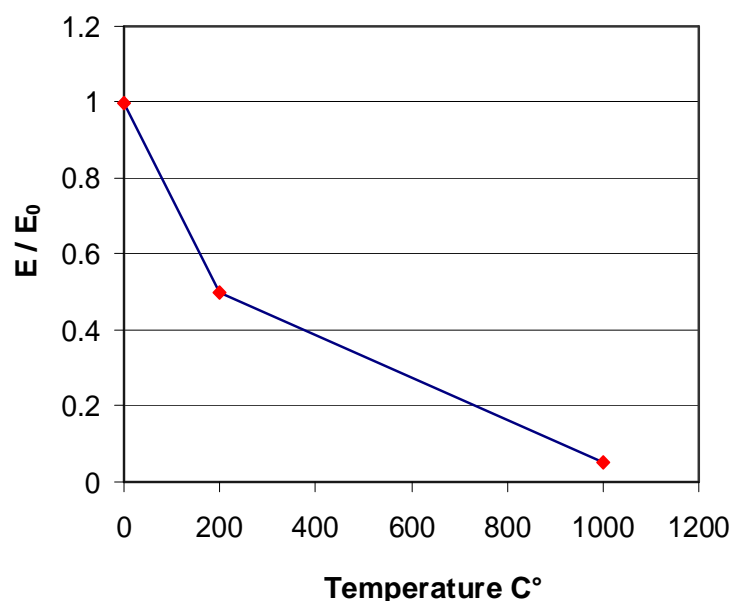

Figure (7) Concrete Elastic modulus

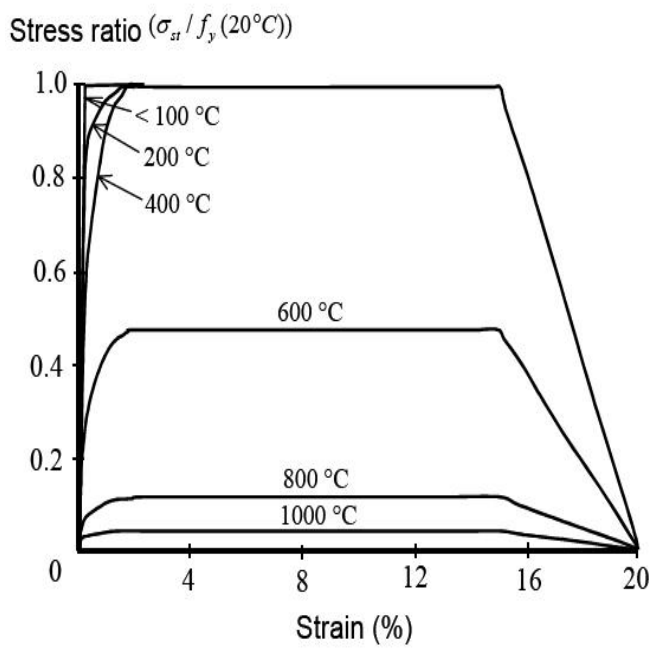

Figure (9) Steel Stress - Strain[2] 


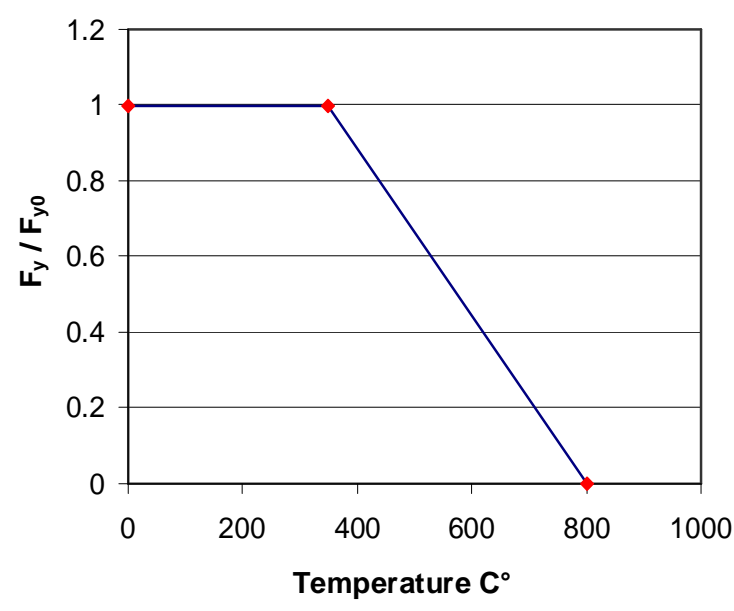

Figure (10) Steel Tensile strength

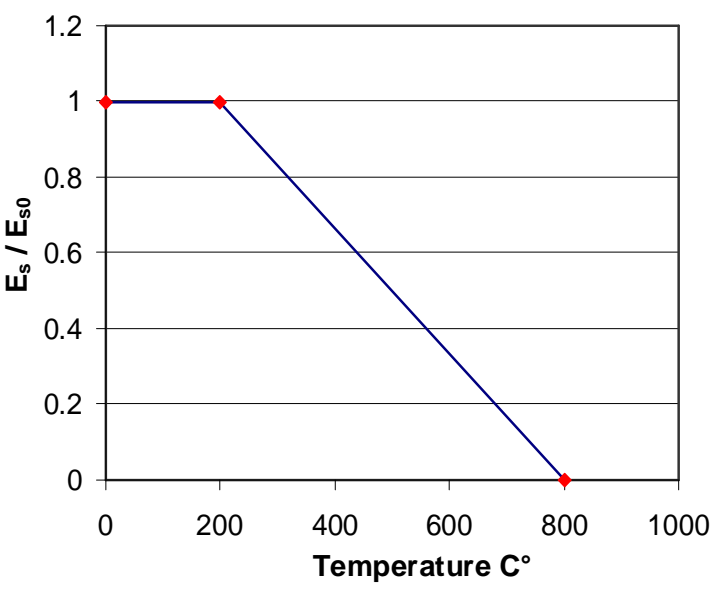

Figure (11) Steel Elastic modulus[2]

\section{Numerical Fire Test Simulation}

\section{Example (1) One-way slab}

In this example, one-way R.C. slab test from reference [3] is simulated in fig. (12) Half slab mesh of (28 elements) and (10 layers) is shown. The slab is simply supported along short side while the other two sides are free. The test was carried under external line load on above face, slab material specifications explained in table (1).Experimental fire temperature variation with time is shown in fig (13).

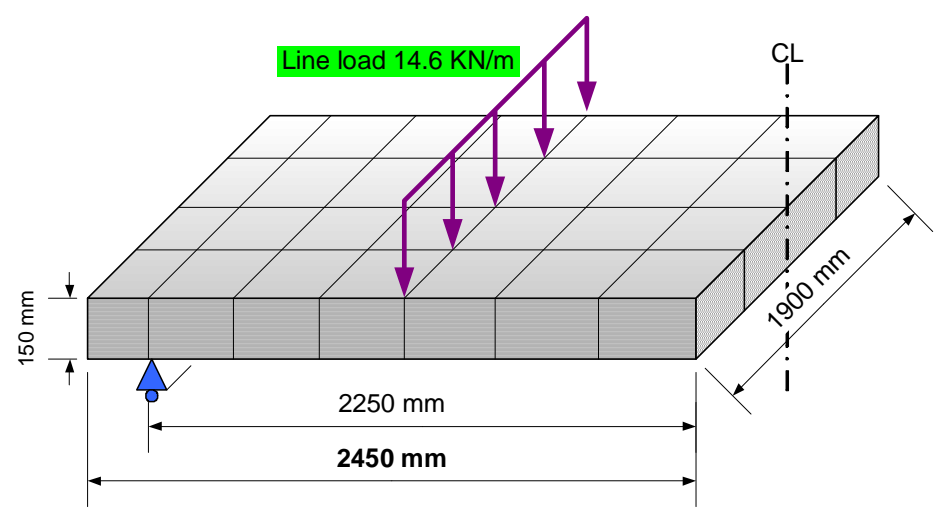

Figure (12) One way half slab [3]

Table (1)

\begin{tabular}{|c|c|c|c|}
\hline Reinforcement $\left(\mathrm{mm}^{2}\right)$ & 1414 & & \\
\hline Line Load $(\mathrm{kN} / \mathrm{m})$ & 14.6 & & \\
\hline \multicolumn{4}{|c|}{ Properties } \\
\hline Concrete & & Steel & \\
\hline $\mathrm{E}\left(\mathrm{N} / \mathrm{mm}^{2}\right)$ & 39800 & $f_{y}\left(\mathrm{~N} / \mathrm{mm}^{2}\right)$ & 504 \\
\hline$f_{c}\left(\mathrm{~N} / \mathrm{mm}^{2}\right)$ & 43.0 & $\mathrm{E}\left(\mathrm{N} / \mathrm{mm}^{2}\right)$ & 215000 \\
\hline$f_{t}\left(\mathrm{~N} / \mathrm{mm}^{2}\right)$ & 2.6 & & \\
\hline
\end{tabular}




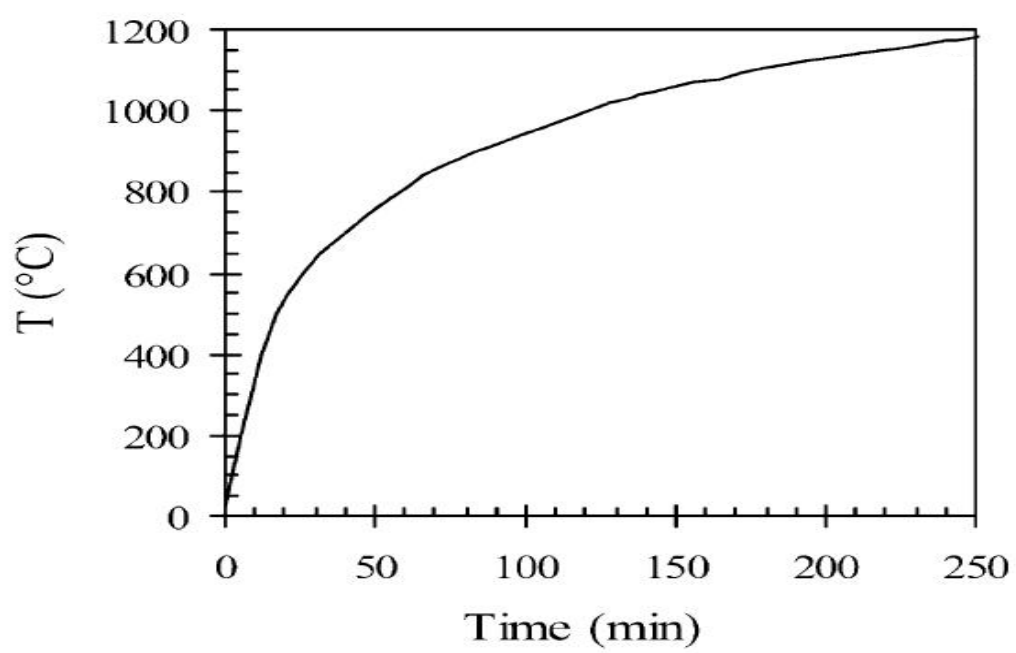

Figure (13) Fire history of the experimental test[3]

Eight node layered shell element is used in the analysis with selective integration. Linear variation of temperature through thickness with $13 \%$ of temperature in top face is assumed. The total load is applied on slab before any temperature rising. After that, the temperature increased with increments until failure. The steel reinforcement is assumed to have temperature the same as concrete temperature at the location of steel.

A Comparison of numerical and experimental results is shown. The time deflection curve is shown in fig. (14), the good agreement between the test and the analysis indicates that the proposed model is consistent and can be used with confidence.

The horizontal normal stresses on the cross section at the center of the slab at time $(0$, 20, and 60) min are shown in fig (15). It is clear from this figure that concrete layers can reach failure by cracking with time increasing, this means that the slab bottom layer will crack due to:

- Increase in curvature of slab.

- Decrease of concrete and steel strengths.

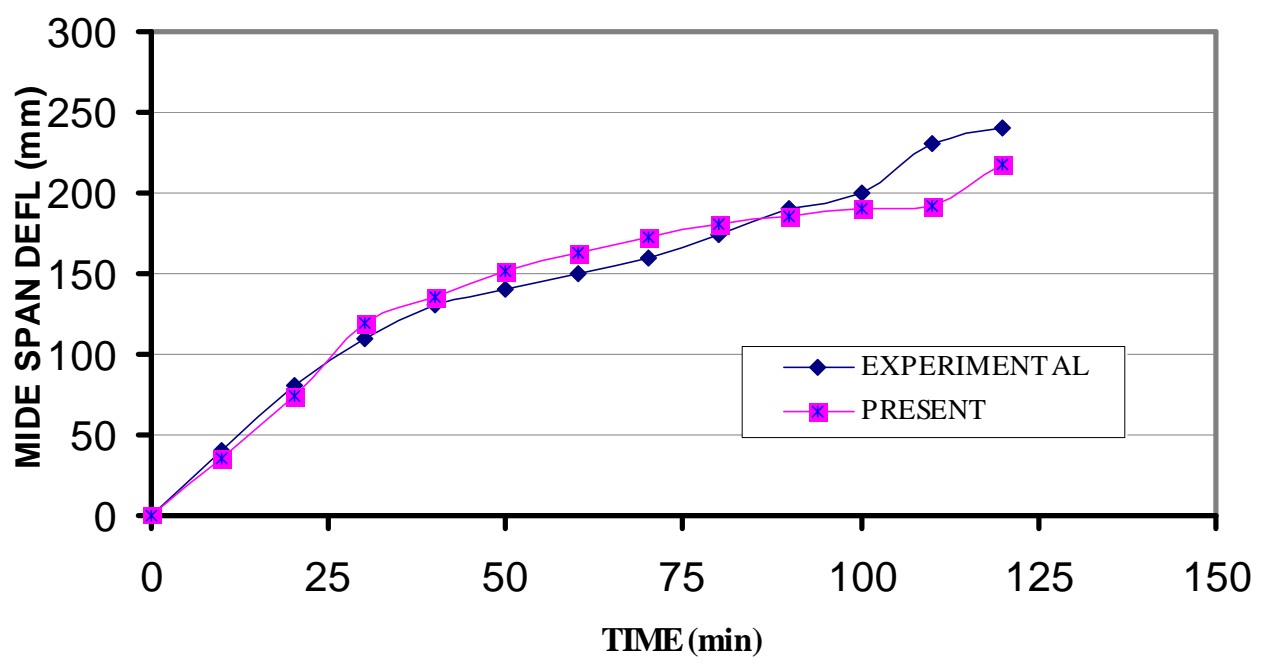

Figure (14) Mid slab deflection with time. 


\section{$\begin{array}{llll}\text { Al-Rafidain Engineering } & \text { Vol.17 No.3 } & \text { June } 2009\end{array}$}

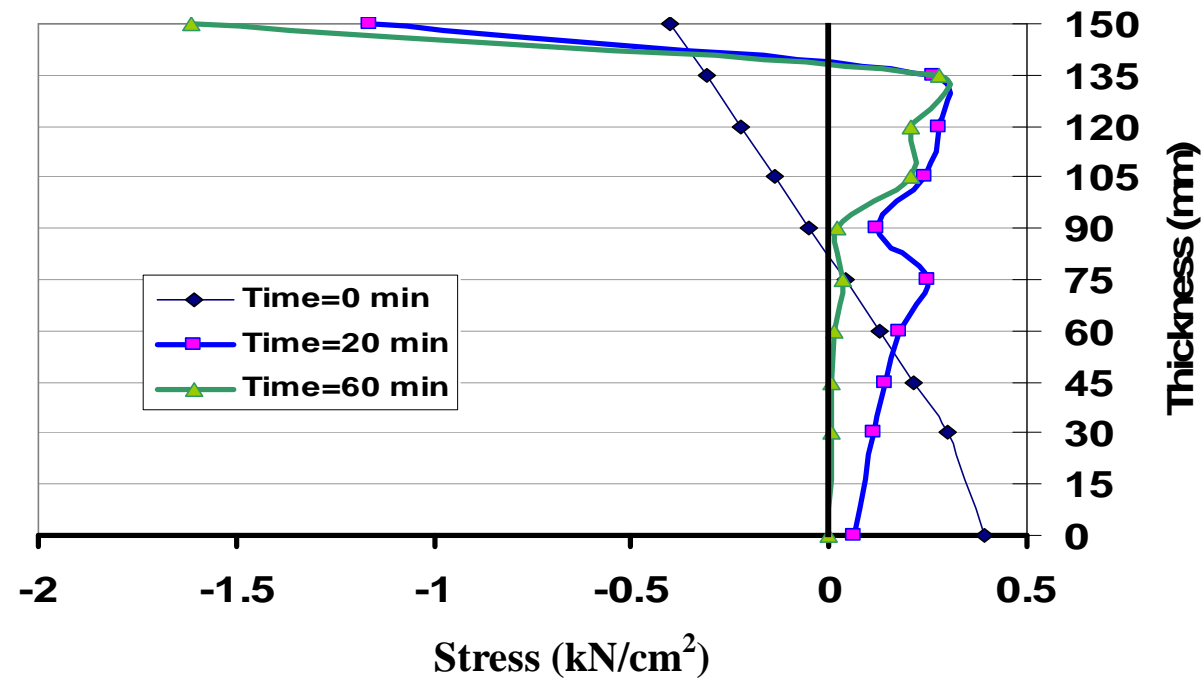

Figure (15) Mid slab stress distribution

\section{Example (2) Two - way slab}

The full-scale two way R.C. slab (D147) which was tested experimentally by Linus and Wadam [11] is considered here to test and verify the present work. The slab is simply supported at all sides, and fixed at the four corners to prevent lifting up. The Slab properties are given in table (2). The reinforcement is a single layer in the bottom. Experimentally, the applied load was (200 liter) drums distributed on slab as external service load before firing start. Finite element meshing is shown in fig. (16), the slab is idealized by 16 elements with 10 concrete layers through the thickness.

The fire test history with time is shown in fig (17), where the experimental test tried to simulate ISO - fire standard curve compared with actual measured temperature at bottom face of slab.

In the numerical simulation, the assumed percentage of temperature transfer from bottom face to top face is (13.5\%). The behaviors of slab (D147) with F.E. simulation is shown in fig. (18) Compared with experimental results. The slab reached failure at time (123 min) whith equivalent temperature of $\left(940 \mathrm{C}^{\circ}\right)$ with geometrical non-linear solution, but experimentally slab failed at time (140 $\mathrm{min})$, when the numerical analyses ignore geometrical non-linearity the slab will fail at time $(60 \mathrm{~min})$. Cracks pattern are checked in present analysis at bottom face of slab (face near to fire) and compared with the experimen as shown in fig. (19) and fig. (20), the crack direction is diagonal near the slab corner but parallel to the supporting line at middle strip of slab.

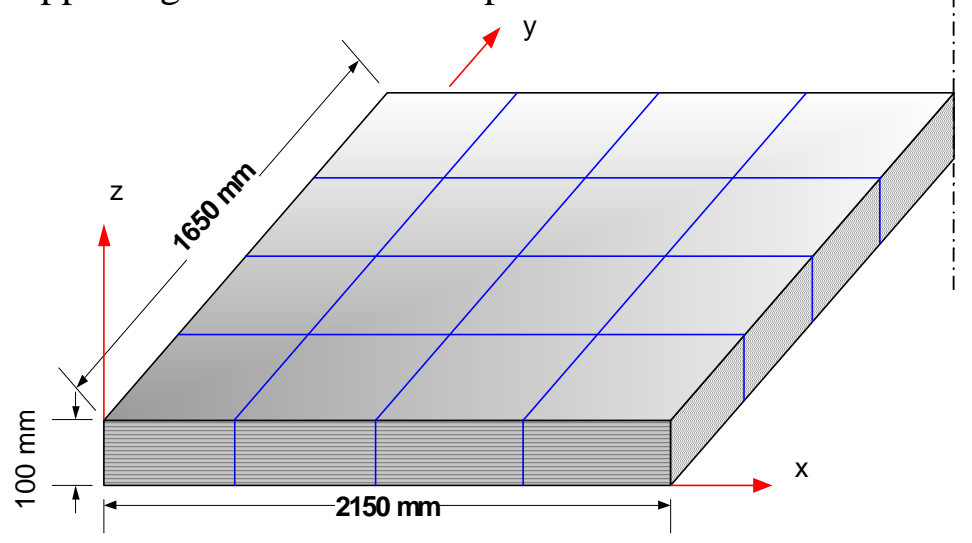

Figure (16) Two-way slab element mesh
Table (2)

\begin{tabular}{|c|c|}
\hline $\begin{array}{c}\text { Reinforcement } \\
\left(\mathrm{mm}^{2}\right)\end{array}$ & $\mathbf{1 9 8}$ \\
\hline Load $\left(\mathrm{kN} / \mathrm{m}^{2}\right)$ & $\mathbf{5 . 4 0}$ \\
\hline \multicolumn{2}{|c|}{ Properties } \\
\hline Concrete & \\
\hline $\mathrm{E}\left(\mathrm{N} / \mathrm{mm}^{2}\right)$ & $\mathbf{3 9 8 0 0}$ \\
\hline$f_{c}\left(\mathrm{~N} / \mathrm{mm}^{2}\right)$ & $\mathbf{3 6 . 6}$ \\
\hline$f_{t}\left(\mathrm{~N} / \mathrm{mm}^{2}\right)$ & $\mathbf{3 . 6}$ \\
\hline Steel & \\
\hline$f_{y}\left(\mathrm{~N} / \mathrm{mm}^{2}\right)$ & $\mathbf{5 6 5}$ \\
\hline $\mathrm{E}\left(\mathrm{N} / \mathrm{mm}^{2}\right)$ & $\mathbf{2 1 5 0 0 0}$ \\
\hline
\end{tabular}


Al-Saati: Analysis Of R.C. Slabs At High Temperature Using Nonlinear Finite Element

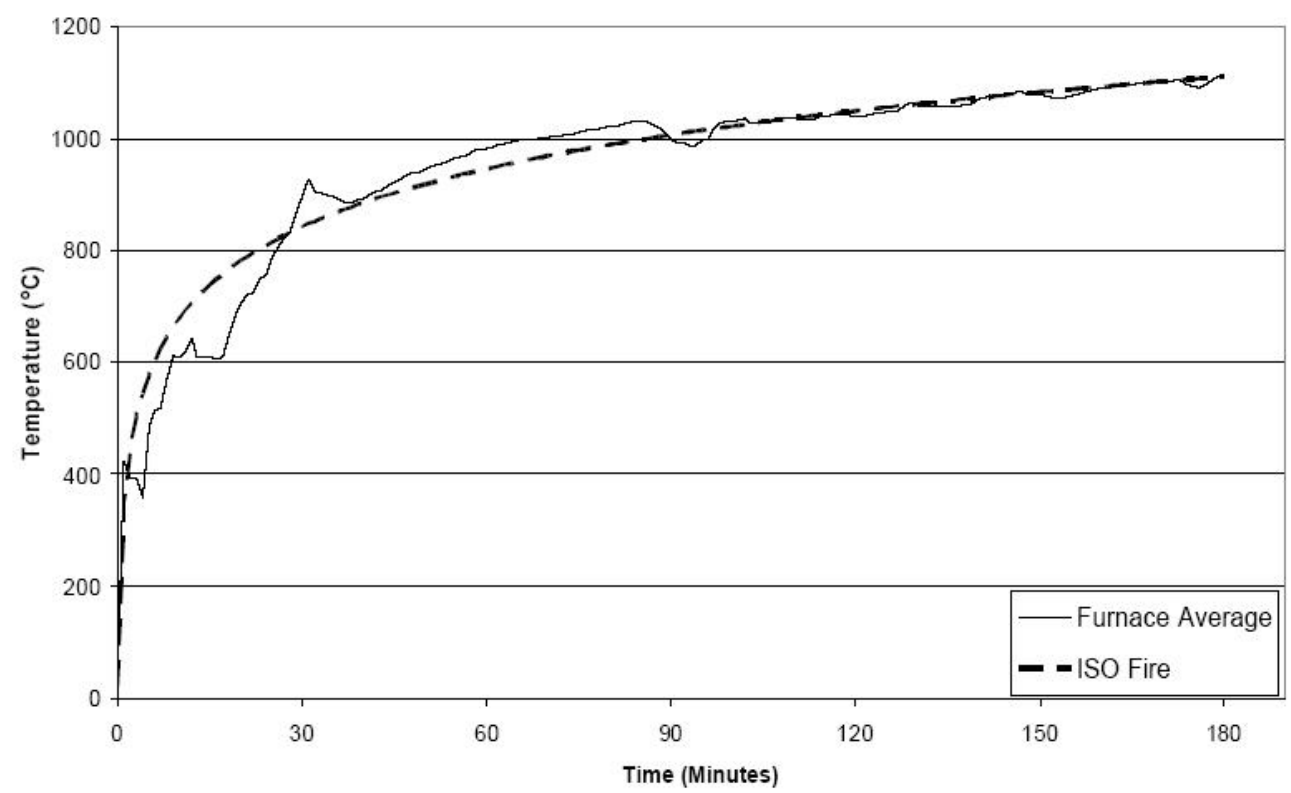

Figure (17) Fire history in experimental test [11]

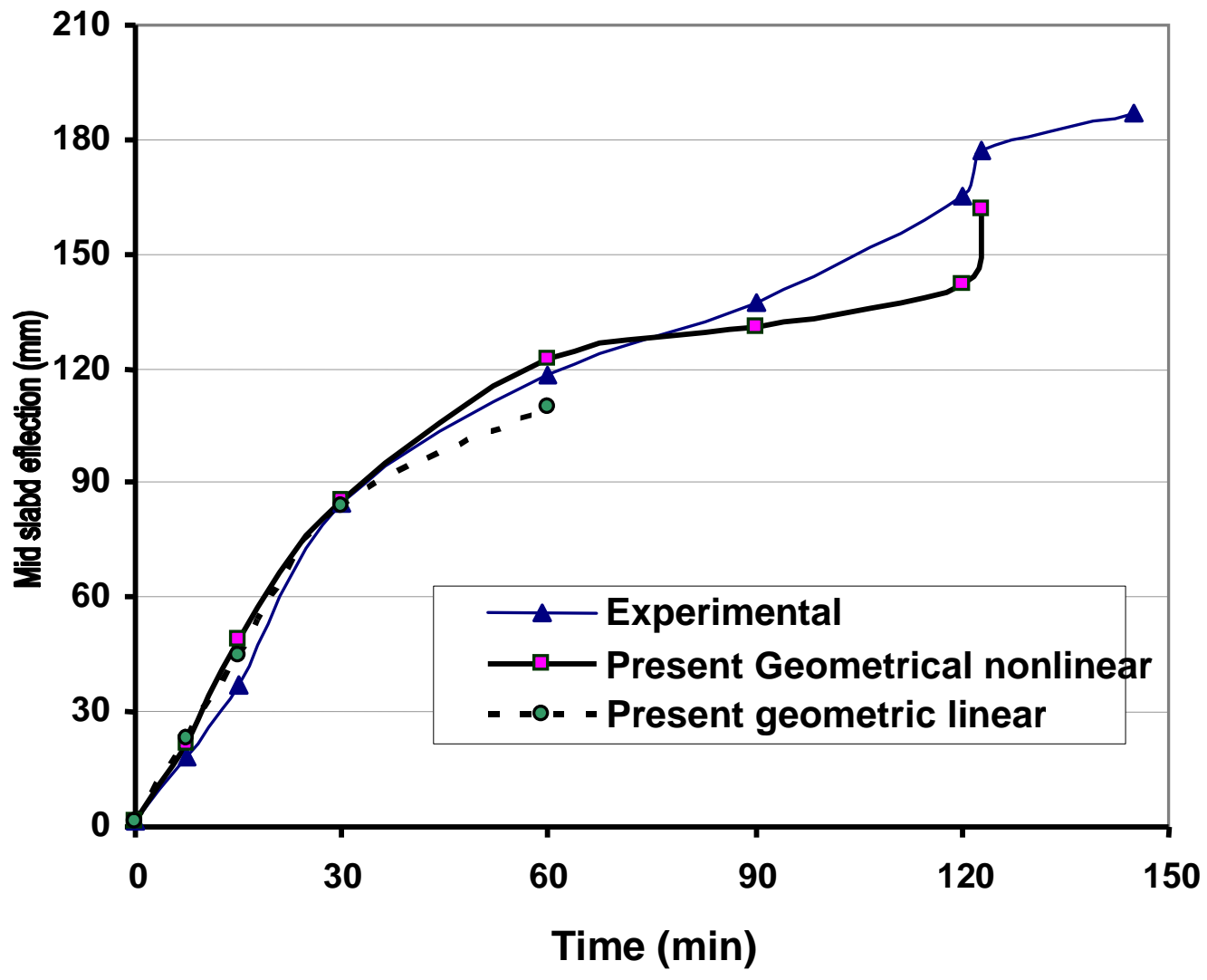

Figure (18) Mid slab deflection with time 
$\begin{array}{llll}\text { Al-Rafidain Engineering } & \text { Vol.17 No.3 } & \text { June } 2009\end{array}$

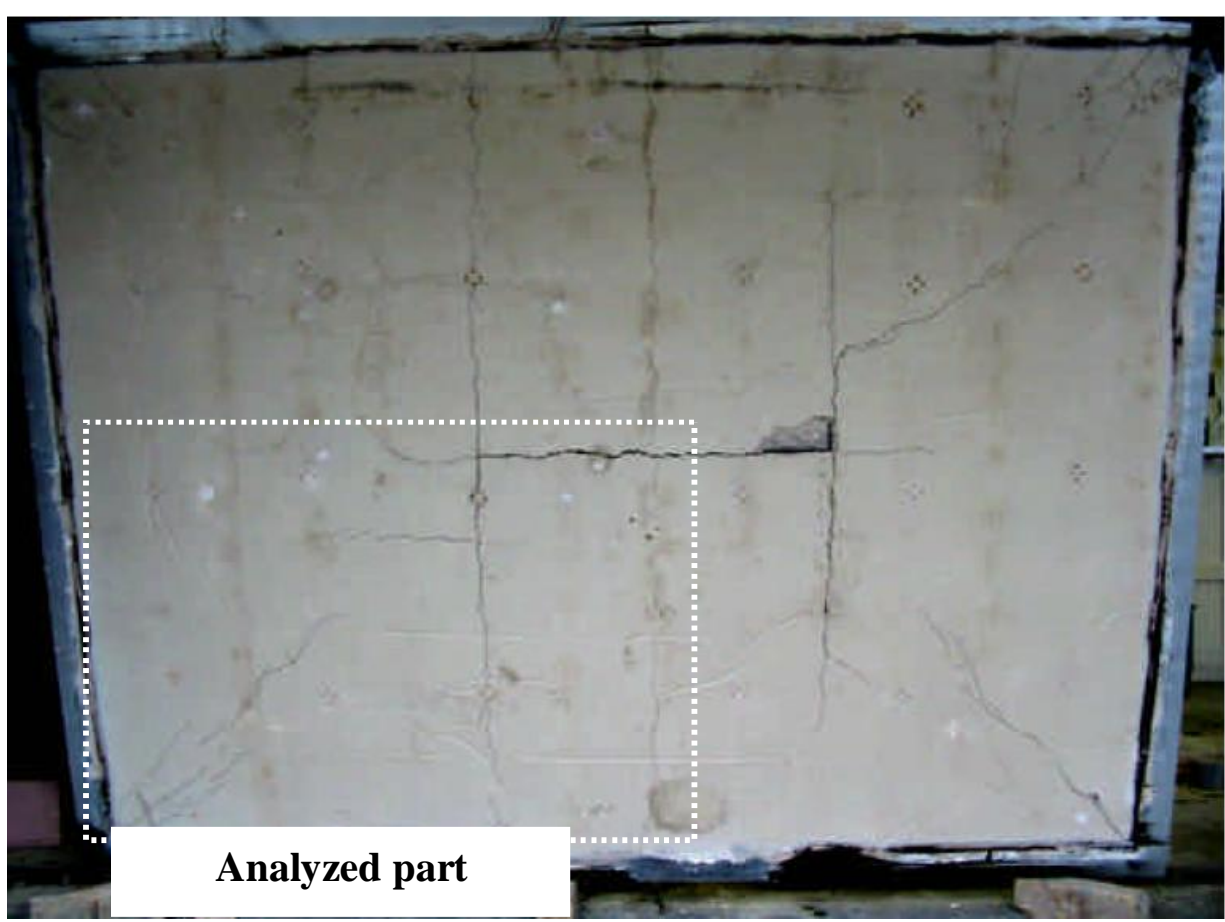

Figure (19) Experimental Crack pattern in bottom face of slab (D147) [11]

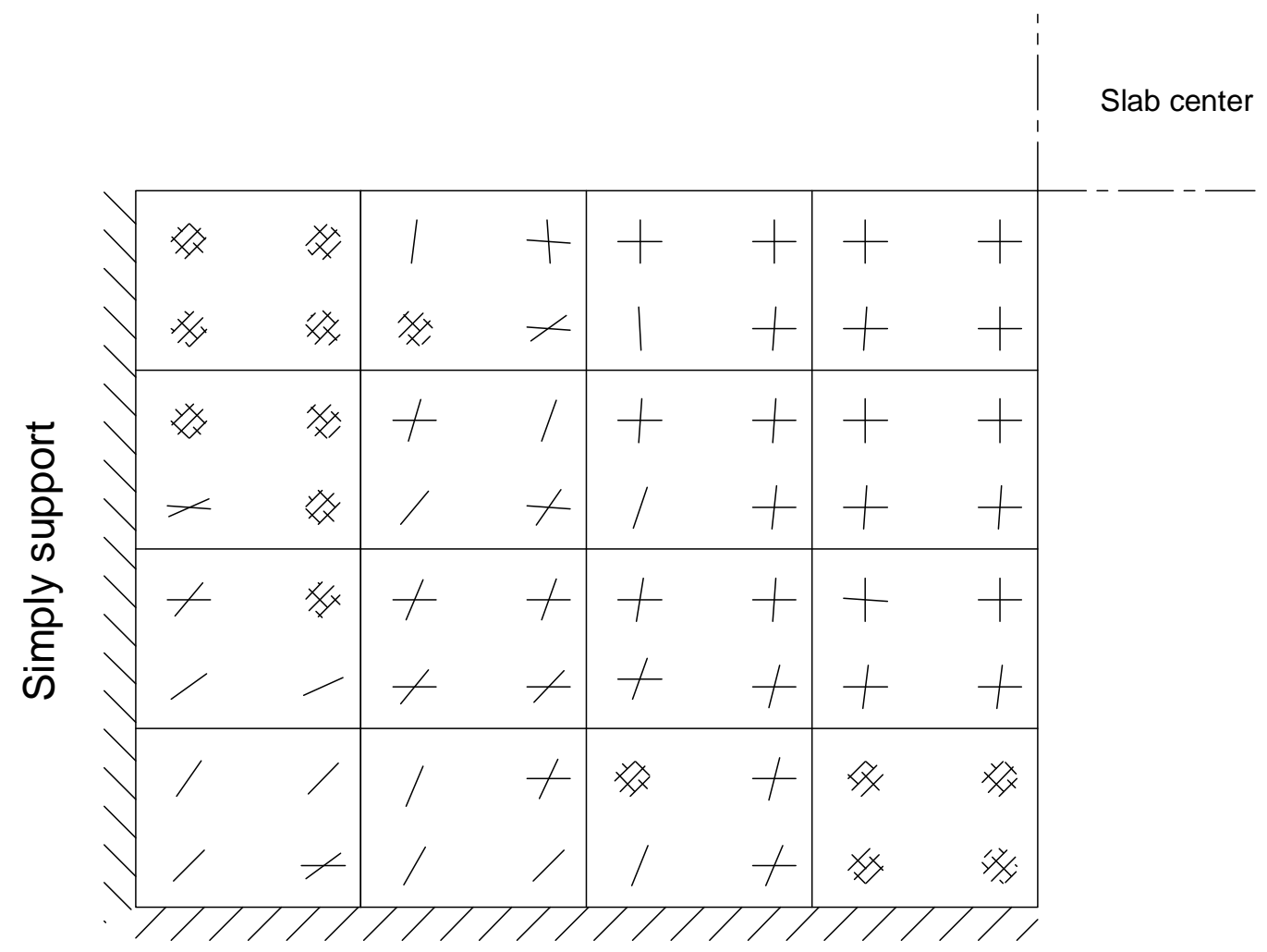

Simply support

Figure (20) Present Crack pattern in bottom face of slab 


\section{Conclusion}

1. The Assumption of linear temperature distribution through slab thickness, gives acceptable simulation.

2. Shell element gives a good simulation of slab fire analysis with large deformation formulation.

3. Appling load on slabs before firing gives acceptable results consisted with experimental results.

4. When the slab temperature becomes very high and deflection becomes large the influence of membrane tension in the slab becomes very important in supporting slab loading.

5. Neutral axis moves up with time until become full crack section after (60 min).

6. Stress at top face increases with time until reaching (4 times) of initial mechanical stress before firing.

7. Geometrical nonlinear analysis is required in firing analysis problems.

8. The model for fire analysis may be combined with heat transfer through structure to find more accurate behavior of structure.

9. From the time-deflection, curve it shown that present models give more stiff response than experimental at last stage of firing. This means that creep and shrinkage strain should be considered.

\section{References}

[1] Nizamuddin, Z. T. 'Thermal and structural analysis of reinforced concrete slabs in fire environments. ' $\mathrm{PhD}$ thesis, Univ. of California, Berkeley, Calif. 1976.

[2] Zhaohui Huang, Ian Burgess and Roger J. Plank,' Modeling membrane action of concrete slabs in composite building in fire. I: Theoretical development', JOURNAL of structural engineering, Vol. 129, No.8, 2003.

[3] W. Nechnech, F. Meftah and J.M. Reynouard 'elasto - plastice damage model for plain concrete subjected to high temperatures', ENGINEERING STRUCTURE 24 (2002) 597611.

[4] Eurocode 2, 2002. Design of concrete structure, Part 1-2: General rule - structural fire design, prEN 1992-1-2.

[5] Igor Planine, Sebastjan Bratina, Bojan Gas and Miran Saje,' Numerical modeling of behavior of reinforce concrete columns in fire and comparison with eurocode 2', SOLID AND STRUCTURES 42 (2005) 5715-5733.

[6] Long - yuan Li and Joun Purkiss, 'Stress - Strain constitutive of equations of concrete material at elevated temperatures ', FIRE SAFTY JOURNAL 40 (2005) 669-686.

[7] X.X. Zha,' FE analysis of fire resistance of concrete filled CHS columns ', JOURNAL OF CONSTRUCTIONAL STEEL RESEARCH 59 (2003) 769-779.

[8] E. Hinton and D.R. Owen, Finite element Plate and Shell, Pineridge Press, Swansee, 1984.

[9] Antonio R. Mari,' Non- linear geometric, material and time dependent analysis of three dimensional reinforced and pre -stressed concrete frames ', STRUCTURAL ENGINEERING AND STRUCTURAL MECHANICS report No. UBC/SESM-84/12, BERKELEY.

[10] Abdolkarim Abbasi and Paul J. Hogg,' A model for prediction of the constituents of a glass fiber rebar reinforced concrete beam at elevated temperatures simulating a fire test , , COMPOSITES PART B 36 (2005) 384-393.

[11] Linus Lim and Colleen Wadem, 'Experimental fire test of tow way slabs', University of Canterbury (FIRE ENGINEERING RESEARCH REPROT 02/12) New Zeland.

The work was carried out at the college of Engg. University of Mosul 